\title{
Envelhecimento bem-sucedido e autoeficácia: Uma revisão da literatura
}

Self-efficacy and successful aging: a literature review

Envejecimiento exitoso y autoeficacia: una revisión de la

literatura

Milena Bianca Aragão De Nadai

Lahis da Silveira Pinheiro

Denise Mendonça de Melo

RESUMO: O envelhecimento bem-sucedido não apresenta uma definição consensual, porém é representado por idosos ativos. A autoeficácia é um autorregulador de capacidades próprias para a execução de ações, visando a determinadas realizações. O objetivo do estudo foi realizar uma revisão da literatura sobre o envelhecimento bem-sucedido e a autoeficácia. A literatura oferece indícios de que a autoeficácia seja um dos determinantes para uma velhice bem-sucedida.

Palavras-chave: Autoeficácia; Envelhecimento bem-sucedido; Idosos.

ABSTRACT: Successful aging does not have a conceptual definition, however it is represented by active seniors. The self-efficacy is a high regulator of their own capacities for the execution of actions aiming at certain realizations. The objective of this study was to conduct a review of the literature on successful aging and self-efficacy. The literature offers evidence that self-efficacy is one of the determinants of successful old aging.

Keywords: Self-efficacy; Successful aging; Elderly. 
RESUMEN: El envejecimiento exitoso no tiene una definición consensuada, pero está representado por personas mayores activas. La autoeficacia es un autorregulador de sus propias habilidades para realizar acciones, con el objetivo de ciertos logros. El objetivo del estudio fue revisar la literatura sobre envejecimiento exitoso y autoeficacia. La literatura proporciona evidencia de que la autoeficacia es uno de los determinantes de la vejez exitosa. Palabras clave: Autoeficacia; Envejecimiento exitoso; Personas mayores.

\section{Introdução}

O número de idosos tem crescido em grande escala no Brasil, o que tem levado a muitas investigações sobre o envelhecimento, pois se entende que, com o passar dos anos, essa população irá aumentar (Acosta, \& Deponti, 2010). De acordo com dados demográficos do Instituto Brasileiro de Geografia e Estatística (IBGE, 2010), em 2013, a população idosa correspondia a 14,9 milhões (7,4\% do total), com estimativa de crescimento para 58,4 milhões (26,7\% do total) em 2060. Esse crescimento da população idosa provoca mudanças no perfil demográfico, além de desafios na promoção de saúde e prevenção de doenças nessa fase da vida (Miranda, Mendes, \& Silva, 2016).

Segundo a Organização das Nações Unidas, na I Assembleia Mundial sobre Envelhecimento em Viena (ONU, 1982) o ingresso na velhice se dá por um critério social, que determina que pessoas consideradas idosas são aquelas que possuem 60 anos ou mais em países em desenvolvimento e 65 anos ou mais em países desenvolvidos. Considerando a amplitude dessa etapa da vida, existe uma estratificação etária da velhice para tentar respaldar a sua heterogeneidade, que é: 65 a 74 anos (idoso jovem), 75 a 84 anos (idoso idoso) e 85 anos ou mais (idoso mais velho) (Papalia, Olds, \& Feldman, 2013). A esse respeito, considere-se o que apontam Oliveira, Côrte e Lopes (2018, p. 29):

Ao falar de velhice e envelhecimento, cria-se um dilema, pois, em muitos aspectos, a velhice é singular e não se pode dizer, categoricamente, que depois de certa idade o indivíduo se torna velho. Ser idoso envolve aspectos relativos aos anos vividos e como dada cultura concebe esse fato. É recomendável insistir na ideia de que o envelhecimento não é somente um 
momento da vida, mas um processo complexo que requer mais estudos para ser compreendido, tanto por quem o vivencia, como pela sociedade.

Não obstante a diferenciação cronológica que se costuma estabelecer, há que se destacar que essa etapa da vida é marcada por uma grande distinção de aspectos multidimensionais do desenvolvimento humano (Papaléo-Neto, 2013), englobando os domínios físico, social, psicológico e cognitivo.

Dentro do segmento populacional idoso existem diferentes perfis de velhice, que geram tipos distintos de envelhecimento, sendo o normal, o patológico e o ótimo ou bemsucedido (Neri, \& Yassuda, 2008).

De acordo com a literatura da gerontologia existe certa dificuldade em diferenciar a velhice normal da patológica, dado que o envelhecimento, ao acarretar, muitas vezes, efeitos complicados à saúde, estes são distintos em velocidade, duração e intensidade (Papaléo-Neto, 2013).

A velhice normal é a que mais abrange grande número de idosos, pois não foca apenas a saúde, mas também o bem-estar subjetivo, psicológico, físico e sociocultural (Neri, \& Yassuda, 2008). Existem peculiaridades que são específicas e imprescindíveis desse envelhecimento (Neri, 2007a). No decorrer dos anos acontecem transformações biológicas no corpo de todo o indivíduo, acarretando obstáculos comuns a eles em um processo normativo e global, não trazendo, porém, prejuízos na vivência do que se caracterizaria como uma velhice normal (Boechat, \& Rodrigues, 2017). É preciso, porém, que não se deixe de lembrar que o envelhecimento e a velhice estão sempre ligados a cuidados de uma pessoa consigo mesma durante toda uma vida, considerando-se que "o cuidado é condição essencial para que o envelhecimento possa se dar da forma desejada, bem-sucedida”. É preciso durante a vida preparar, da melhor forma que nos seja possível, a velhice (Lodovici, 2018, p. 7).

De qualquer forma, a despeito dos desejados cuidados, a velhice pode se caracterizar como patológica, quando há o aparecimento ou uma piora de doenças crônicas que vão diminuir gradativamente a capacidade do idoso em fazer suas atividades de costume (Neri, \& Yassuda, 2008). A pessoa pode se tornar dependente em decorrência do aparecimento de doenças reversíveis, ou irreversíveis, de caráter debilitante. Relaciona-se normalmente com eventos biológicos, porém podem se ligar a eventos externos como os psicossociais (Neri, \& Yassuda, 2008). 
Velhice ótima ou bem-sucedida é caracterizada por pessoas que não possuem dependência contínua ou de dependência de cuidadores em atividades cotidianas; são autônomas e ativas em seu meio social, chegando a contribuir para a sociedade por meio de suas capacidades (Neri, \& Yassuda, 2008).

Não existe uma definição consensual desse tipo de velhice; apesar disso, ela é considerada uma meta a ser atingida, uma velhice "ideal" (Papaléo-Neto, 2013). Esse perfil de envelhecimento é também caracterizado pela proporcionalidade entre perdas e ganhos obtidos pela idade (Azzi, \& Fontes, 2012). Alguns autores utilizam descritores diferentes para o envelhecimento bem-sucedido como, por exemplo, envelhecimento saudável ou envelhecimento ativo (Carielo, 2016).

Rowe e Kahn (1997) sugeriram que idosos com características fisiológicas e psicossociais acima da média poderiam ser identificados como aqueles que estariam vivendo um processo de envelhecimento saudável. A Organização Mundial de Saúde (OMS, 2005) utiliza o termo envelhecimento ativo, que é entendido como uma melhoria na saúde, na atividade social, na participação cultural e econômica, promovendo melhor qualidade na última etapa do ciclo vital.

Um estudo multicêntrico com o objetivo de pesquisar o envelhecimento bem-sucedido entre idosos de diversas regiões do Brasil foi realizado por Neri, et al. (2013), utilizando os termos envelhecimento saudável e envelhecimento feliz. A pesquisa teve como meta averiguar a interpretação de idosos sobre velhice saudável e ser feliz na velhice, levando em consideração fatores socioeconômicos, de gênero, idade, renda e status conjugal. A pesquisa foi realizada com 2.242 idosos de seis localidades brasileiras, com 65 anos ou mais. A maior parte eram mulheres, idosos entre 65 a 79 anos, com renda pessoal menor que cinco salários mínimos e idosos casados. Os resultados mostram que envelhecimento saudável e feliz são termos vinculados a um bom relacionamento familiar e interpessoal, ter saúde cognitiva e física, bem-estar psicológico, autoestima, autoconhecimento, religiosidade, entre outros fatores.

Lucca, Mantovani e Neri (2016) também investigaram possíveis determinantes do envelhecimento saudável e ser feliz na velhice. O estudo foi feito com 1.242 idosos com 65 anos ou mais, residentes de duas cidades brasileiras (Belém, PA, e Campinas, SP). Obtiveram resultados para as questões relacionadas ao envelhecimento saudável e ser feliz na velhice, deixando em evidência que envelhecer bem e ser feliz na velhice não é apenas a ausência de 
doenças, envolvendo múltiplos fatores, tais como: relação entre duas pessoas ou mais e o bem-estar psicológico.

De acordo com Boechat e Rodrigues (2017), o ponto de partida para o envelhecimento bem-sucedido é acreditar em si mesmo e fazer acontecer. Acredita-se que um dos fatores que contribuem para o envelhecimento bem-sucedido é a autoeficácia, que é descrita por Bandura (2008), em sua Teoria Social Cognitiva, como sendo um autorregulador de capacidades próprias para a execução de ações, visando a determinadas realizações.

A Teoria Social Cognitiva (TSC), proposta pelo psicólogo Albert Bandura, é uma teoria recente que ainda se encontra em construção. Sua proposta central está ancorada na perspectiva da agência para o autodesenvolvimento, mudança e adaptação, pressupondo, portanto, que o ser humano seja ativo diante de seu processo de desenvolvimento (Bandura, 2008). Sugere que as pessoas não sejam meramente produto de suas circunstâncias de vida, mas, sim, autoorganizadas, proativas, autorreguladas e autorreflexivas (Bandura, 2008). Compreende o pensamento e a ação humanos como produto da interação recíproca e dinâmica entre influências pessoais, comportamentais e ambientais (Pajares, \& Olaz, 2008). As referidas crenças de autoeficácia estão localizadas no núcleo fundamental da Teoria Social Cognitiva (Pajares, \& Olaz, 2008).

Lima, Oliveira e Silva (2016) realizaram uma pesquisa validando a escala de autoeficácia para a autodireção na saúde dos idosos. O estudo foi feito com 508 pessoas, entre elas adultos maduros e idosos, de 51 a 96 anos, residentes em Portugal. Os resultados mostram que idosos com crenças positivas de autoeficácia possuem eficiência em cuidar da própria saúde; já os que não possuem essa eficiência, obtiveram resultados mais baixos para a autodireção na saúde.

A autoeficácia é caracterizada pelas crenças que fazem com que um idoso tenha maior discernimento sobre sua vida, tornando-se e sentindo-se mais ativo em suas escolhas (Neri, 2007b). Essas crenças se moldam às novas rotinas, concepções e entendimento diante do mundo e sociedade, à medida em que as pessoas envelhecem, formando novas crenças de acordo com suas novas competências (Neri, 2007b).

Um estudo realizado em 2006, por Jopp e Rott, mostra a relação entre autoeficácia e o envelhecimento. Participaram da pesquisa 51 idosos, e nela foram averiguadas quais as relações de recursos básicos, como saúde, cognição, autoeficácia, e redes sociais, com a felicidade. Foi indicado nos resultados que os idosos, mesmo aqueles que possuem limitações cognitivas e físicas, decorrentes do envelhecimento, reconheciam-se felizes. 
Em relação à autoeficácia, os resultados evidenciaram que ela auxilia na diminuição do sofrimento causado pelas perdas, sendo um fator de proteção nesta fase da vida e uma ajuda na adaptação às mudanças (Azzi, \& Fontes, 2012).

Tendo em vista a suposta relação entre envelhecimento bem-sucedido e autoeficácia, esta pesquisa teve como objetivo realizar uma revisão da literatura brasileira sobre essas duas variáveis. Especificamente intencionou-se conhecer mais as temáticas: envelhecimento bemsucedido e autoeficácia, identificando a forma como pesquisadores brasileiros estudam e investigam essa possível relação, discutindo a produção acadêmica referente aos artigos disponíveis nas bases de dados Scientific Electronic Library Online (SciELO Brasil, 2017) e Periódicos Eletrônicos em Psicologia (PePSIC Brasil, 2017).

\section{Métodos}

A pesquisa foi realizada por meio de revisão da literatura, com buscas nas bases de dados nacionais SciELO e PePSIC, nos dias cinco e seis de agosto de 2017. A escolha dos artigos não teve delimitação temporal, e foram usados como descritores isolados os termos envelhecimento bem-sucedido, envelhecimento ativo, envelhecimento saudável e autoeficácia; e como descritores em pares, envelhecimento bem-sucedido e autoeficácia, envelhecimento ativo e autoeficácia e envelhecimento saudável e autoeficácia. Foram conferidos os títulos e os resumos de cada artigo encontrado nas bases de dados eletrônicas, e utilizados os que preenchiam os critérios de inclusão. Os critérios para a inclusão foram: serem artigos científicos que tratassem sobre os temas do estudo, artigos empíricos ou de revisão de literatura e que envolvessem pesquisas com pessoas com idade igual ou superior a 50 anos, ou seja, adultos maduros e idosos. Os critérios para a exclusão foram: artigos escritos em idioma estrangeiro ou que não versassem sobre o tema do estudo e artigos que explicitassem estudar o envelhecimento normal e patológico. Uma vez formado o conjunto de artigos, todos foram lidos por completo. O fluxograma, exposto na figura 1, demonstra os conjuntos de estudos encontrados em cada base, inclusos ou não, avaliados para o desenvolvimento dessa pesquisa. A análise de dados foi feita por meio de análise de conteúdo (Bardin, 2011). Utilizou-se também a estatística descritiva contendo média, que foi realizada no software Excel 2016. 
Foram adotadas duas bases de dados, SciELO e PePSIC, por serem portais que abrangem uma coleção selecionada de periódicos científicos, contribuindo para o conhecimento de forma confiável e segura. Além dessas características, a base de dados PePSIC é uma fonte virtual de informação na área de saúde, reunindo as principais revistas de psicologia.

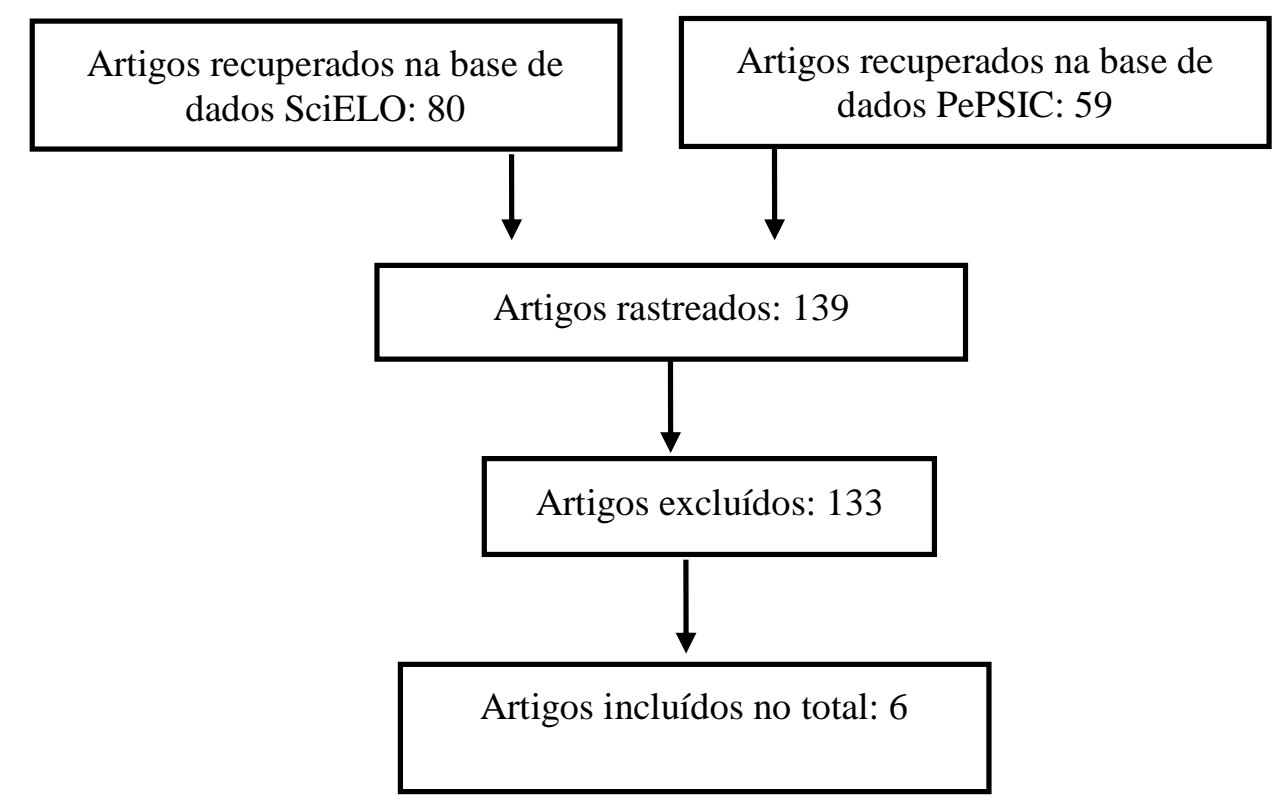

Figura 1. Fluxograma para composição da amostra de artigos analisados.

Para uma melhor disposição estrutural, apresenta-se no Quadro I, a seguir, a caracterização dos seis textos selecionados para integrar a discussão, contendo: Base de dados, ano da publicação; nome dos autores; nomes dos periódicos de publicação; métodos e títulos. 


\begin{tabular}{|c|c|c|c|c|c|}
\hline $\begin{array}{l}\text { Base de } \\
\text { Dados }\end{array}$ & $\begin{array}{l}\text { Ano do } \\
\text { Artigo }\end{array}$ & Autoria & $\begin{array}{l}\text { Periódico de } \\
\text { Publicação }\end{array}$ & Método & Título \\
\hline SciELO & 2007 & $\begin{array}{l}\text { Cupertino, A., Rosa, F., \& } \\
\text { Ribeiro, P. }\end{array}$ & $\begin{array}{l}\text { Psicologia: Reflexão e } \\
\text { crítica }\end{array}$ & $\begin{array}{l}\text { Pesquisa } \\
\text { quanti }\end{array}$ & $\begin{array}{l}\text { Definição de Envelhecimento } \\
\text { Saudável na Perspectiva de } \\
\text { Indivíduos Idosos }\end{array}$ \\
\hline SciELO & 2010 & $\begin{array}{l}\text { Lautert, L. \& Silva, M. C. } \\
\text { S. }\end{array}$ & $\begin{array}{l}\text { Revista Escola de } \\
\text { Enfermagem USP }\end{array}$ & $\begin{array}{l}\text { Pesquisa } \\
\text { quali }\end{array}$ & $\begin{array}{l}\text { O senso de autoeficácia na } \\
\text { manutenção de comportamentos } \\
\text { promotores de saúde de idosos }\end{array}$ \\
\hline SciELO & 2012 & $\begin{array}{l}\text { Azzi, R. G., \& Fontes, A. } \\
\text { P. }\end{array}$ & Estudos de Psicologia & $\begin{array}{l}\text { Revisão de } \\
\text { literatura }\end{array}$ & $\begin{array}{l}\text { Crenças de autoeficácia e } \\
\text { resiliência: apontamentos da } \\
\text { literatura sociocognitiva }\end{array}$ \\
\hline SciELO & 2012 & $\begin{array}{l}\text { Ferreira, O., Maciel, S., } \\
\text { Costa, S., Silva, A., \& } \\
\text { Moreira, M. }\end{array}$ & $\begin{array}{l}\text { Texto Contexto } \\
\text { Enfermagem }\end{array}$ & $\begin{array}{l}\text { Pesquisa } \\
\text { quanti }\end{array}$ & $\begin{array}{l}\text { Envelhecimento ativo e sua } \\
\text { relação com a independência } \\
\text { funcional }\end{array}$ \\
\hline SciELO & 2015 & $\begin{array}{l}\text { Sousa, E. M. S., \& } \\
\text { Oliveira, M. C. C. }\end{array}$ & $\begin{array}{lr}\text { Revista Brasileira de } \\
\text { Geriatria } & e \\
\text { Gerontologia } & \end{array}$ & $\begin{array}{l}\text { Pesquisa- } \\
\text { ação }\end{array}$ & $\begin{array}{l}\text { Viver a (e para) aprender: uma } \\
\text { intervenção-ação para a } \\
\text { promoção } \\
\text { envelhecimento ativo }\end{array}$ \\
\hline Pepsic & 2013 & $\begin{array}{l}\text { Karlinski, L. P. B., \& } \\
\text { Frassetto, S. S. }\end{array}$ & Aletheia & $\begin{array}{l}\text { Pesquisa } \\
\text { quali }\end{array}$ & $\begin{array}{l}\text { A percepção de idosas acerca } \\
\text { das crenças de autoeficácia } \\
\text { e envelhecimento saudável }\end{array}$ \\
\hline
\end{tabular}

Quadro 1. Caracterização dos textos que compõem o presente estudo

\section{Resultados}

Compuseram a amostra seis artigos que se referiram ao tema envelhecimento bemsucedido e autoeficácia, abrangendo o período de 2007 a 2015. Na base de dados SciELO, 
foram recuperados 80 estudos, sendo que cinco cumpriram os critérios de inclusão e foram selecionados. Na base de dados PePSIC, foram encontrados 59 estudos e apenas um preencheu os critérios de inclusão. O maior número de publicações foi encontrado no ano de 2012 ( $\mathrm{n}=2 ; 33,33 \%$ ). Nos anos de 2008, 2009, 2011 e 2014 não foram encontradas pesquisas referentes ao tema. O web qualis (indicador de qualificação de periódicos) de cada revista em que foram extraídos os artigos foram pesquisados na Plataforma Sucupira e analisados. A maioria variou entre A1 e A2 (n=4; 66,67\%); o restante variou entre B1 e B2 (n=2; 33,33\%). Dentre os artigos pesquisados, aproximadamente $33,33 \%(\mathrm{n}=2)$ foram publicados em revistas de psicologia; aproximadamente 33,33\% ( $\mathrm{n}=2)$ em revistas de enfermagem; e os demais em revistas multidisciplinares. Com o descritor autoeficácia, foram encontradas duas pesquisas $(33,33 \%)$; com o descritor envelhecimento ativo, também foram encontradas duas pesquisas; e com o descritor envelhecimento saudável, igualmente, foram encontradas duas pesquisas; que, somadas, totalizaram 66,67\% dos estudos analisados. Utilizando-se descritores em pares foi encontrada somente uma pesquisa referente à autoeficácia e envelhecimento saudável.

Dentre as pesquisas recuperadas, cinco eram estudos empíricos $(83,33 \%)$ e uma pesquisa $(16,67 \%)$ era de revisão da literatura. Com referência aos artigos empíricos, um foi realizado em Portugal, porém foi publicado no Brasil; as demais pesquisas foram realizadas no nordeste, sudeste e sul brasileiro. Os artigos que discutiram a relação entre autoeficácia e envelhecimento bem-sucedido foram três (50\%); o restante apresentou questões ligadas somente ao tema envelhecimento bem-sucedido. O número de participantes investigados nas pesquisas empíricas foi de, no mínimo seis e, no máximo, 501. Apenas um estudo utilizou somente pessoas do sexo feminino; o restante incluiu amostras dos dois sexos. As amostras das pesquisas foram coletadas em Unidades Básicas de Saúde da Família, centros de lazer e entre idosos residentes nas comunidades, entre idosos residentes na comunidade, e uma pesquisa não se refere ao local de coleta de dados.

\section{Discussão}

Esta revisão da literatura brasileira visou a investigar a suposta relação entre o envelhecimento bem-sucedido e a autoeficácia, por meio de artigos científicos. Foram encontrados poucos artigos referentes ao tema, possivelmente devido ao fato de o termo envelhecimento bem-sucedido ser algo recente e sua definição não consensual. 
Outro possível fator limitante para a pesquisa são as alterações demográficas brasileiras relacionadas à idade, que são relativamente recentes; assim, o interesse dos pesquisadores acompanha a demanda social. De acordo com Neri e Jorge (2006), o estudo do envelhecimento no Brasil ainda tem uma forte ideia de patológico, e isso faz com que novos estudos sobre velhice bem-sucedida não tenham muito espaço no campo de pesquisa. Os conceitos de doença e idoso frágil ainda têm definições resistentes para a sociedade e no campo da pesquisa, sendo um limitador muito grande quando se trata de investigações que busquem estudar uma velhice normativa ou ideal.

Mesmo sendo um estudo livre em um universo temporal, foi percebido que o interesse pelo tema é recente, pois não foram encontrados artigos anteriores ao ano de 2007, o que mostra a importância de melhor definir o conceito de envelhecimento bem-sucedido e seus determinantes como a autoeficácia. Tais discussões podem contribuir para o empoderamento dos idosos, via aumento da autoeficácia, pois a sociedade ainda apresenta atitudes negativas em relação à velhice e isso pode causar a diminuição do senso de autoeficácia, prejudicando a saúde dos idosos e a vivência de um envelhecimento bem-sucedido.

De acordo com Ribeiro (2015), historicamente o fato de o termo envelhecimento bemsucedido ter sido pouco estudado também se explica, pois foi somente em meados do século $\mathrm{XX}$ que ocorreu um aumento do interesse pelas ciências do envelhecimento humano. Tal aumento ocorreu devido ao crescimento do número de pessoas idosas em várias localidades do mundo. Foi observada uma separação entre os cientistas da gerontologia; alguns davam ênfase às perdas advindas da velhice e a outra parte tinha uma perspectiva voltada para o envelhecimento ativo. De acordo com Cupertino, Rosa e Ribeiro (2007), as pesquisas realizadas em meados do século XX davam maior ênfase às fases da infância e adolescência, e tratavam o envelhecimento como um declínio no desenvolvimento humano, não como uma fase contínua a ser estudada. Já na época atual, século XXI, o meio acadêmico busca ultrapassar condutas negativas relativas ao envelhecimento, estigmas e preconceitos que ainda existem na sociedade, compreendendo a temática do envelhecimento (Ribeiro, 2015).

Das pesquisas incluídas nesta revisão da literatura, duas abordaram a percepção da pessoa idosa acerca do envelhecimento bem-sucedido (Cupertino, et al., 2007; Frassetto, \& Karlinsk, 2013). Somente um estudo foi de revisão de literatura e ele discorreu sobre a relação entre autoeficácia e resiliência nas diferentes fases da vida, inclusive no envelhecimento (Azzi, \& Fontes, 2012). 
Um estudo dissertou sobre o envelhecimento ativo e a independência funcional do idoso (Costa, Ferreira, Maciel, Moreira, \& Silva, 2012); outro mostrou a relação da autoeficácia com comportamentos que promovem a saúde na pessoa idosa (Lautert, \& Silva, 2010). Uma investigação realizou uma intervenção para a promoção do envelhecimento ativo (Oliveira, \& Sousa, 2015).

De acordo com Costa, et al. (2012) para se alcançar um envelhecimento ativo, é importante existirem, na sociedade, projetos voltados para a promoção de saúde e prevenção de doenças, além daqueles que buscam preservar a autonomia nesta fase da vida. Um dos estudos incluídos nesta revisão, realizado por Costa, et al. (2012), analisou o que estabelece um envelhecimento ativo e sua associação com a independência funcional. A pesquisa foi realizada com 100 idosos, dentre eles, $40 \%$ não eram escolarizados e $48 \%$ possuíam o ensino fundamental incompleto. Como resultado, verificou-se que todos os idosos que participaram do estudo apresentavam independência funcional. Com isso, foi possível verificar que a maioria deles eram pessoas mais ativas, física e cognitivamente, possuíam uma boa relação com a comunidade, a família e amigos, mantinham atividades relacionadas ao lazer e atividades domésticas, não sendo pessoas sedentárias. Essas condições são consideradas típicas de um envelhecimento ativo.

Um dos estudos incluídos nesta pesquisa, desenvolvido por Oliveira, et al. (2015), discorre também sobre o envelhecimento ativo, e teve como objetivo levar, a idosos de um centro de convivência em Portugal, atividades que pudessem proporcionar um envelhecimento ativo; atividades essas que foram divididas em cinco temas: momentos de lazer e aprendizagem, informática, educação ambiental, educação para a saúde e intergeracionalidade. $\mathrm{O}$ estudo foi feito com 12 adultos maduros e idosos, de 50 a 85 anos. Através do resultado, foi possível observar que as atividades propostas, além de terem sido prazerosas para os participantes, lhes deram novas perspectivas que contribuíram para melhor eficiência no dia a dia, tornando-os mais independentes, ativos, e com uma melhor qualidade de vida. A pesquisa buscou mostrar a importância de se promoverem atividades para motivação a um envelhecimento ativo, levando, aos idosos, informações úteis e de grande valia para eles.

Essas duas pesquisas citadas anteriormente possuem resultados semelhantes. Foi visto que o envelhecimento ativo depende de fatores que se associam com a independência, ser ativo na vida e não ser uma pessoa sedentária, além de possuir uma boa relação familiar e com a comunidade. Estes fatores dependem de uma forte crença de autoeficácia, pois esta 
crença refere-se à expectativa de que seja possível, através do esforço pessoal, realizar com sucesso uma determinada tarefa e alcançar um resultado (Neves, \& Faria, 2009). Muitas vezes, apesar de as pessoas saberem bem o que fazer e de possuírem até as capacidades necessárias, elas não agem de maneira eficaz. Além das capacidades para a execução de dada tarefa, é preciso que o indivíduo acredite que suas ações possam gerar os resultados esperados, ou então terá pouco incentivo para perseverar frente a uma dificuldade (Pajares, \& Olaz, 2008).

De acordo com a OMS (2005), o envelhecimento ativo diz respeito a um idoso atuante em suas interações sociais, que possua uma boa qualidade de vida, tenha práticas saudáveis, bem-estar mental e físico e que mantenha a independência e autonomia. Este termo não se refere somente à ausência de doenças, mas também a um envelhecimento participativo e bemsucedido, que engloba fatores psicológicos, fisiológicos, sociais e culturais.

Uma pesquisa realizada por Cupertino, et al. (2007), incluída neste estudo, buscou saber o que envelhecimento saudável significa para os próprios idosos. A amostra foi composta por 501 idosos, entre 60 e 93 anos, da cidade de Juiz de Fora, MG. Os aspectos mais abordados pelos idosos foram relações interpessoais, saúde física, manter boa alimentação, praticar exercícios, saúde emocional e evitar situações de risco. Foi mínima a ocorrência de interpretações que viam o envelhecimento como algo patológico, o que mostra alterações no estereótipo da velhice como uma fase de perdas. De acordo com Valer, Bierhals, Aires e Paskulin (2015), o envelhecimento saudável é visto de forma diferente por cada pessoa, e uma única pessoa pode ter muitos conteúdos e opiniões importantes sobre este tema, podendo mostrar significados amplos sobre ele. Este fato também se relaciona à autoeficácia, pois esta é definida como a opinião de uma pessoa sobre suas capacidades em produzir níveis de desempenho designados que exercem influência sobre os eventos que afetam suas vidas (Collares, 2011).

Somados à autoeficácia elevada, outros fatores podem influenciar a vivência do envelhecimento bem-sucedido, conforme informações obtidas pelos artigos recuperados nesta revisão de literatura. $\mathrm{O}$ envelhecimento bem-sucedido se dá pelas condições de manter uma boa dieta, controle da ingestão de bebidas alcoólicas, término do hábito de fumar, pouca chance de doenças, bom desempenho físico e mental e relação eficaz com a vida (Neri, 2006). De acordo com Baltes e Baltes (1990), o envelhecimento bem-sucedido se dá também por seleção, otimização e compensação (SOC). Seleção significa selecionar objetivos; otimização 
é indicada pela criação de condições mais favoráveis para se atingir o objetivo; já a compensação deve ser buscada quando a maneira de atingir os objetivos estiver indisponível. Esta teoria pode ser aplicada em todo o desenvolvimento humano e se relaciona com perdas e ganhos, havendo adaptação nos recursos para estabelecimento dos objetivos existentes. Tal adaptação se dá pela plasticidade comportamental em que o indivíduo modifica os fatores internos e externos para diminuir as perdas e aumentar os ganhos (Neri, 2006).

De acordo com Neri (2007c), o envelhecimento bem-sucedido não se limita à saúde e ao engajamento social; ele depende de o idoso selecionar comportamentos nos quais apresenta melhor desempenho, de otimizar esse desempenho por meio de métodos que compensem as perdas nesta fase da vida. A teoria da seleção, otimização e compensação ocorre ao longo da vida, mas é na velhice que ela ganha uma dinâmica nova em decorrência dos declínios sociais, biológicos e mentais que podem ocorrer nessa fase (Neri, 2007c). Selecionar, otimizar e compensar podem constituir determinantes mais robustos para o envelhecimento bemsucedido quando somados às crenças positivas de autoeficácia. Se uma pessoa possui uma crença positiva em sua autoeficácia, possivelmente terá maior êxito em realizar suas tarefas ou passar por adversidades e, caso encontre dificuldades, conseguirá superá-las. Caso contrário, uma pessoa com uma crença negativa poderá ter mais dificuldade na realização de tarefas (Bandura, 2008).

Segundo Pajares \& Olaz (2008), existem quatro tópicos que podem influenciar na formação das crenças de autoeficácia no indivíduo: experiência de domínio, experiência vicária, persuasões sociais e estados somáticos e emocionais. A experiência de domínio diz respeito a resultados de comportamentos realizados vistos como positivos, aumentando a chance desses comportamentos se repetirem no futuro. Experiência vicária ocorre quando um indivíduo observa outro semelhante agindo em alguma tarefa e isso propicia mais confiança para realizar o que deseja. Persuasões sociais ocorrem quando pessoas são expostas a críticas verbais, sejam positivas ou negativas; as positivas irão estimular o aumento da crença de autoeficácia, enquanto as negativas irão desestimular essas crenças e enfraquecê-las. Os estados somáticos e emocionais são reações fisiológicas como determinantes para a autoeficácia. Mudanças fisiológicas podem gerar emoções negativas, medos e ansiedade, ao realizar alguma tarefa.

De acordo com Júnior e Resende (2008), a autoeficácia também é de grande importância para o envelhecimento bem-sucedido, por permitir que os idosos desenvolvam uma boa memória. 
Uma crença positiva da autoeficácia mostra que a pessoa confia que tem competência para se lembrar de informações; já pessoas com uma baixa autoeficácia não se sentem competentes sobre suas lembranças. Para estes autores, a autoeficácia permite aos idosos se integrarem melhor nesta nova fase, se adaptando a fatores internos e externos, afetando de forma positiva o bem-estar e desempenhos sociais e cognitivos (Júnior, \& Resende, 2008).

Uma pesquisa realizada por Frassetto e Karlinsky (2013), que atendeu aos critérios de inclusão desta revisão de literatura, dispôs como objetivo saber qual a percepção de idosas acerca do envelhecimento bem-sucedido e das crenças de autoeficácia. $\mathrm{O}$ estudo foi feito com seis idosas que possuíam entre 70 a 80 anos. Os resultados mostraram que idosas com crença positiva de autoeficácia acreditam em um envelhecimento bem-sucedido, não se sentem limitadas, são resilientes, confiantes e se valem da religiosidade como enfrentamento aos problemas que lhes surjam. As questões mais destacadas foram a aceitação da velhice, espiritualidade, ausência de limitações, resiliência, integração social, visão do futuro e questões de temperamento.

Outro estudo, também incluído nesta pesquisa, igualmente relaciona a autoeficácia com o envelhecimento, e foi realizado por Lautert e Silva (2010), tendo como objetivo entender a importância da autoeficácia na preservação de comportamentos que promovem a saúde na velhice. A pesquisa foi feita com onze idosos de um centro de lazer em Porto Alegre, estado do RS, possuindo 60 anos ou mais. Como resultado, foi visto que indivíduos que possuíam um senso positivo da autoeficácia mantinham comportamentos saudáveis. As questões que receberam mais ênfase foram: atitudes pessoais positivas, expectativa de viver mais tempo, dar prioridade a comportamentos saudáveis e expectativa de viver melhor. $\mathrm{O}$ medo da finitude, da dependência física e o desejo de viver mais e melhor também foram motivadores para a promoção desses comportamentos.

Os estudos de Frassetto e Karlinsky (2013) e Lautert e Silva (2010) são complementares, pois mostram que existe a relação entre o envelhecimento bem-sucedido e a autoeficácia. Idosos com uma crença positiva em sua autoeficácia buscam comportamentos que promovam sua saúde, são resilientes, enfrentando dificuldades de forma ativa, buscam viver melhor, possuem boas relações interpessoais e aceitam a velhice.

De acordo com Azzi e Fontes (2012), em uma revisão bibliográfica que foi incluída neste estudo, o envelhecimento bem-sucedido se associa a uma boa autoeficácia e a resiliência. 
A resiliência teria como finalidade preservar um desempenho adaptativo durante a vida, resultando em uma estabilidade entre perdas e ganhos na velhice; ela é uma forma de enfrentamento e adaptação positiva às circunstâncias adversas.

Nas pesquisas empíricas incluídas neste estudo, em relação à amostra, prevaleceu em maior quantidade o número de mulheres. Esta situação se explica, de acordo com Neri (2007), devido ao fato de as mulheres viverem mais do que os homens, e isso ocorre, pois as doenças que acometem homens e mulheres nesta fase são distintas. Entre os homens idosos é mais comum doenças letais, como as cardiopatias. Em mulheres idosas as doenças não letais são mais incidentes, podendo ocasionar enfermidades crônicas e incapacidades. Mesmo as mulheres vivendo mais do que os homens, elas não vivem melhor; são mais acometidas de incapacidade, depressão, doenças crônicas e problemas de morbidade.

Um estudo realizado por Bueno e Lima (2009) por meio de revisão da literatura, teve como objetivo refletir sobre o tema do envelhecimento feminino. O número de idosas é superior ao número de idosos no Brasil, e isso se deve ao fato de que o envelhecimento é vivenciado de maneira diferente pela mulher, devido à circunstância de viverem mais, elas são mais frágeis às doenças incapacitantes e crônicas. As mulheres vivem mais, mas muitas vezes falta-lhes qualidade de vida. Foi observado, com a pesquisa citada anteriormente, que são escassas as ações que promovem a saúde das mulheres idosas, e será necessário a presença destas, não somente acrescentando dias nas vidas dessas mulheres, mas também dias com qualidade durante o processo de envelhecimento, alcançando uma velhice bem-sucedida.

O estudo do envelhecimento bem-sucedido é de grande importância e um conceito padrão sobre este perfil de velhice não é simples de ser definido, pois cada indivíduo dá um significado próprio para o sucesso e o que é ser bem-sucedido. De acordo com Neri e Teixeira (2008), patologias, morbidades e limitações não são fatores que impedem uma velhice bemsucedida; é de grande valia levar em conta os significados pessoais da palavra sucesso. Existem muitas formas de perceber e estimar a própria vida; portanto, determinar o que é ser "bem sucedido" é uma visão muito simples entre fracasso e sucesso.

\section{Considerações finais}

O objetivo deste estudo foi realizar uma revisão da literatura sobre as variáveis envelhecimento bem-sucedido e autoeficácia. 
Foram analisados os estudos levantados para esta pesquisa, identificando conjuntos de ideias centrais e relevantes que contribuíram para alcançar o objetivo da mesma, sugerindo que a autoeficácia seja um possível determinante para uma velhice bem-sucedida.

De acordo com Neri (2007), mesmo a velhice bem-sucedida não possuindo uma definição consensual, ela é caracterizada por idosos ativos e autônomos em seu meio social. A autoeficácia é definida pelas crenças que fazem com que os indivíduos tenham maior discernimento sobre a sua vida. Estes dois termos se relacionam no sentido de que a autoeficácia positiva pode proporcionar à pessoa idosa uma melhor qualidade de vida, moldando a rotina, concepções, entendimento diante do mundo e sociedade. Os idosos formam novas crenças de autoeficácia de acordo com as competências que adquirem ao longo da vida.

Apesar de este estudo ter alcançado os objetivos pretendidos, algumas limitações podem ser percebidas. Dentre os fatores limitante, é possível citar que poucos artigos foram incluídos na presente revisão, porque a literatura nacional não apresenta expressiva produção sobre o envelhecimento bem-sucedido, tendo como determinante a autoeficácia. Possivelmente seja válido, em análises subsequentes, investigar o comportamento da mesma relação - envelhecimento bem-sucedido e autoeficácia - também em estudos internacionais.

Salienta-se a utilidade deste estudo como ferramenta de reflexão sobre o envelhecimento bem-sucedido e seus determinantes, destacando a importância do empoderamento do indivíduo idoso tanto em sua própria vida, quanto em sociedade. Recomenda-se novos estudos direcionados à população idosa brasileira, abrangendo também o envelhecimento bem-sucedido. É possível sugerir, por exemplo estudos empíricos que abordem a variável autoeficácia em idosos brasileiros.

\section{Referências}

Acosta, M. A. F., \& Deponti, R. N. (2010). Compreensão dos idosos sobre os fatores que influenciam no envelhecimento saudável. Estudos Interdisciplinares sobre o Envelhecimento, 15(1), 33-52. Recuperado em 01 fevereiro, 2018, de: https://seer.ufrgs.br/RevEnvelhecer/article/view/9520/10908.

Azzi, R. G., \& Fontes, A. P. (2012). Crenças de autoeficácia e resiliência: Apontamentos da literatura sociocognitiva. Estudos de Psicologia, 29(1), 105-114. Recuperado em 01 fevereiro, 2018, de: http://www.scielo.br/pdf/estpsi/v29n1/a12v29n1.pdf. 
Baltes, P. B., \& Baltes, M. M. (1990). Psychological perspectives on successful aging: The model of selective optimization with compensation. In: P. B. Baltes, \& M. M. Baltes. (Orgs.). Successful aging: Perspectives from behavioral sciences. (pp. 1-34). Cambridge: Cambridge University Press.

Bandura, A. (2008) A evolução da teoria social cognitiva. In: A. Bandura, R. G. Azzi, \& S. Polydoro. (Orgs.). Teoria social cognitiva: Conceitos básicos. (pp. 15-41). Porto Alegre, RS: Artmed.

Bardin, L. (2011). Análise de Conteúdo. Luiz Antero Reto e Augusto Pinheiro, Trads. São Paulo, SP: Edições 70, 2011.

Boechat, N. S., \& Rodrigues, V. M. R. (2017). É possível envelhecer bem? Interdisciplinary Scientific Jornal, 4(1), 57-68. Recuperado em 01 fevereiro, 2018, de: http://revista.srvroot.com/linkscienceplace/index.php/linkscienceplace/article/view/305.

Bueno, C. M. L. B., \& Lima, L. C. V. (2009). Envelhecimento e gênero: A vulnerabilidade de idosas no Brasil. Revista Saúde e Pesquisa, 2(2), 273-280. Recuperado em 01 fevereiro, 2018, de: file:///C:/Users/Dados/Downloads/1173-3139-1-PB.pdf.

Carielo, S. C. da. (Org.). (2016). O Envelhecimento Ativo e seus fundamentos. São Paulo, SP: Portal Edições. IBN: 978-85-69350-06-4.

Collares, C. (2011). Autoeficácia nas palavras do próprio Albert Bandura. Recuperado em 01 fevereiro, 2018, de: http://carloscollares.blogspot.com.br/2011/10/autoeficacia-nas-palavrasdo proprio.html.

Correa, M. R., Justo, J. S., \& Rozendo, A. S. (2010). Protagonismo político e social na velhice: Cenários, potências e problemáticas. Revista Kairós-Gerontologia, 13(1), 35-52. $\begin{array}{lllll}\text { Recuperado em } & 01 & \text { fevereiro, }\end{array}$ https://revistas.pucsp.br/index.php/kairos/article/view/4857.

Costa, S. M. G., Ferreira, O. G. L., Maciel, S. C., Moreira, M. A. S. P., \& Silva, A. O. (2012). Envelhecimento ativo e sua relação com a independência funcional. Texto Contexto Enfermagem, 21(3), 513-518. Recuperado em 01 fevereiro, 2018, de: http://www.scielo.br/pdf/tce/v21n3/v21n3a04.

Cupertino, A. P. F. B., Ribeiro, P. C. C., \& Rosa, F. H. M. (2007). Definição de envelhecimento saudável na perspectiva de indivíduos idosos. Psicologia: Reflexão e Crítica, 20(1), 81-86. Recuperado em 01 fevereiro, 2018, de: http://dx.doi.org/10.1590/S010279722007000100011.

IBGE. (2013). Instituto Brasileiro de Geografia e Estatística. Número de Idosos no Brasil vai quadruplicar até 2060. Recuperado em 01 fevereiro, 2018, de: http://www.bbc.com/portuguese/noticias/2013/08/130829_demografia_ibge_populacao_brasil_lgb.

Jopp, D., \& Rott, C. (2006). Adaptation in very old age: Exploring the role of resources, beliefs, and attitudes for centenarians happiness. Psychology and Aging, 21(2), 266-280. Recuperado em 01 fevereiro, 2018, de: https://www.ncbi.nlm.nih.gov/pubmed/16768574.

Júnior, R. L., \& Resende, M. C. (2008). Autoeficácia, memória e envelhecimento. In: A. L. Neri, M. Cachioni \& M. Yassuda (Orgs.), Velhice bem-sucedida: Aspectos afetivos $e$ cognitivos (pp. 127-140). Campinas, SP: Papirus Editora. 
Karlinski, L. P. B., \& Frassetto, S. S. (2013). A percepção de idosas acerca das crenças de autoeficácia e envelhecimento saudável. Aletheia, 42(1), 51-61. Recuperado em 01 fevereiro, 2018, de: http://pepsic.bvsalud.org/scielo.php?script=sci_arttext\&pid=S141303942013000300005 .

Lima, M. P., Oliveira, A. L., \& Silva, G. T. (2016). Envelhecimento e saúde: Escala de autoeficácia para a autodireção [sic] na Saúde. Revista de Saúde Pública, 50(40), 1-9. Recuperado em 01 fevereiro, 2018, de: https://www.scielosp.org/article/ssm/content/raw/?resource_ssm_path=/media/assets/rsp/v50/ pt_0034-8910-rsp-S1518-87872016050006312.pdf.

Lodovici, F. M. M. (2018). Apresentação, pp. 7-14. In: Lodovici, F. M. M. (Org.). Envelhecimento e Cuidados - Uma chave para o viver. São Paulo, SP: Portal Edições. ISBN: 978-85-69350-15-6 (302 p.).

Lucca, S. R., Mantovani, E. P., \& Neri, A. (2016). Associações entre significados de velhice e bem-estar subjetivo indicado por satisfação em idosos. Revista Brasileira de Geriatria e Gerontologia, 19(2), 203-222. Recuperado em 01 fevereiro, 2018, de: http://dx.doi.org/10.1590/1809-98232016019.150041

Miranda, G. M. D., Mendes, A. C. G., \& Silva, A. L. A. (2016). O envelhecimento populacional brasileiro: desafios e consequências sociais atuais e futuras. Revista Brasileira de Geriatria e Gerontologia, 19(3), 507-519. Recuperado em 01 fevereiro, 2018, de: http://dx.doi.org/10.1590/1809-98232016019.150140.

Neri, A. L. (2006). O legado de Paul B. Baltes à psicologia do desenvolvimento e do envelhecimento. Temas em Psicologia, 14(1), 17-34. Recuperado em 01 fevereiro, 2018, de: http://pepsic.bvsalud.org/scielo.php?script=sci_arttext\&pid=S1413-389X2006000100005.

Neri, A. L. (2007a). Paradigmas contemporâneos sobre o desenvolvimento humano em psicologia e em sociologia. In: A. L. Neri. (Orgs.). Desenvolvimento e envelhecimento: Perspectivas biológicas, psicológicas e sociológicas. (pp. 11-38). Campinas, SP: Papirus Editora.

Neri, A. L. (2007b). Crenças de autoeficácia e envelhecimento bem-sucedido. In: E. L. Freitas, F. Cançado, J. Doll, \& M. Garzoni. (Orgs.). Tratado de Geriatria e Gerontologia (pp. 267-1276). Rio de Janeiro, RJ: Guanabara Koogan.

Neri, A. L. (2007c). Qualidade de vida na velhice e subjetividade. In: A. L. Neri (Org.). Qualidade de vida na velhice: Enfoque multidisciplinar. (pp. 13-59). Campinas, SP: Alínea.

Neri, A. (2013). Conceitos e teorias sobre o envelhecimento. In: L. Diniz, R. Cosenza, \& D. Fuentes. (Orgs.). Neuropsicologia do Envelhecimento (pp.17-42). Porto Alegre, RS: Artmed.

Neri, A., \& Jorge, M. D. (2006). Atitudes e conhecimentos em relação à velhice em estudantes de graduação em educação e em saúde: Subsídios ao planejamento curricular. Estudos de Psicologia, 23(2), 127-137. Recuperado em 01 fevereiro, 2018, de: http://dx.doi.org/10.1590/S0103-166X2006000200003.

Neri, A., \& Teixeira, I. (2008). Envelhecimento bem-sucedido: Uma meta no curso da vida. Psicologia Universidade de São Paulo, 19(1), 81-92. Recuperado em 01 fevereiro, 2018, de: http://dx.doi.org/10.1590/S0103-65642008000100010. 
Neri, A., \& Yassuda, M. (2008). Apresentação. In: A. L. Neri, M. Cachioni, \& M. Yassuda. (Orgs.). Velhice bem-sucedida: Aspectos afetivos e cognitivos. (pp. 7-12). Campinas, SP: Papirus Editora.

Neves, S., \& Faria, L. (2009). Autoconceito e autoeficácia: semelhanças, diferenças, interrelação e influência no rendimento escolar. Revista da Faculdade de Ciências Humanas e Sociais. Porto, Portugal: Edições Universidade Fernando Pessoa, 206-218.

Oliveira, A. P. G. de, Côrte, B., \& Lopes, R. G. da C. (2018). O amou(u)r cuidado: condutas, percepções e sentimentos do cônjuge, pp. 25-52. In: Lodovici, F. M. M. (Org.). Envelbecimento e Cuidados - Uma chave para o viver. São Paulo, SP: Portal Edições. ISBN: 978-85-69350-15-6 (302 p.).

Oliveira, M. C. C., \& Sousa, E. M. S. (2015). Viver a (e para) aprender: uma intervenção-ação para a promoção do envelhecimento ativo. Revista Brasileira Geriatria Gerontologia, 18(2), 405-415. Recuperado em 01 fevereiro, 2018, de: http://dx.doi.org/10.1590/18099823.2015.14055.

Organização das Nações Unidas (1982). I Assembleia Mundial sobre Envelhecimento em Viena 1982. Recuperado de https://nacoesunidas.org/acao/pessoas-idosas/.

Organização Mundial da Saúde. (2005). Envelhecimento ativo: uma política de saúde. Suzana Montijo, trad. Brasília, DF: Organização Pan-americana de Saúde.

Pajares, F., \& Olaz, F. (2008). In: A. Bandura, R. G. Azzi, \& S. A. Polydoro. (Orgs.). Teoria social cognitiva: conceitos básicos. (96-114), Porto Alegre: Artmed.

Papaléo Netto, M. (2013). O Estudo da Velhice: Histórico, Definição do Campo e Termos Básicos. In: E. V. Freitas, L. Py, F. A. X., Cançado, J., Doll \& M. Gorzoni. (Orgs.). Tratado de Geriatria e Gerontologia (62-75), Rio de Janeiro, RJ: Guanabara Koogan.

Papalia, D. E., Olds, S. W., \& Feldman, R. D. (2013). Desenvolvimento humano. Porto Alegre, RS: Artmed.

Periódicos Eletrônicos em Psicologia, PePSIC Brasil 2017. Recuperado de: http://pepsic.bvsalud.org/

Plataforma Sucupira 2017. Recuperado de: https://sucupira.capes.gov.br/sucupira/public/ consultas/coleta/veiculoPublicacaoQualis/listaConsultaGeralPeriodicos.jsf.

Ribeiro, P. C. C. (2015). A psicologia frente aos desafios do envelhecimento populacional. Revista Interinstitucional de Psicologia, 8(2), 269-283. Recuperado em 01 fevereiro, 2018, de: http://www.fafich.ufmg.br/gerais/index.php/gerais/article/viewFile/564/385.

Rowe, J., \& Kahn, R. (1997). Successful aging. The Gerontologist, 37(4), 433-440. Recuperado em 01 fevereiro, 2018, de: https://www.ncbi.nlm.nih.gov/pubmed/9279031.

Scientific Electronic Library Online, SciELO Brasil, 2017. Recuperado de: http://www.scielo.br/?lng=pt.

Silva, M. C. S., \& Lautert, L. (2010). O senso de autoeficácia na manutenção de comportamentos promotores de saúde de idosos. Revista Escola de Enfermagem, 44(1), 6167. Recuperado em 01 fevereiro, 2018, de: http://dx.doi.org/10.1590/S008062342010000100009. 
Valer, D. B., Bierhals, C. C. B. K., Aires, M., \& Paskulin, L. M. G. (2015). O significado de envelhecimento saudável para pessoas idosas vinculadas a grupos educativos. Revista Brasileira de Geriatria e Gerontologia, 18(4), 809-819. Recuperado em 01 fevereiro, 2018, de: http://dx.doi.org/10.1590/1809-9823.2015.14042.

Recebido em 23/02/2018

Aceito em 30/06/2018

Milena Bianca Aragão De Nadai - Psicóloga graduada pelo Centro Universitário Estácio Juiz de Fora. Juiz de Fora, RJ. URL: https://orcid.org/0000-0002-0511-4213

milenadenadai25@gmail.com

Lahis da Silveira Pinheiro - Psicóloga graduada pelo Centro Universitário Estácio Juiz de Fora. Juiz de Fora, RJ. URL: https://orcid.org/0000-0001-7693-6663

E-mail: lahispinheiro94@gmail.com

Denise Mendonça de Melo - Doutora em Psicologia, UFJF. Mestre em Gerontologia, Unicamp. Especialista em Desenvolvimento Humano, UFJF, tendo pesquisado sobre o processo de envelhecimento das pessoas com deficiência intelectual. Docente e pesquisadora do curso de Psicologia do Centro Universitário Estácio Juiz de Fora. Juiz de Fora, RJ. URL: https://orcid.org/0000-0002-5324-5875

E-mail: denisemmelo1@gmail.com 